\title{
Study of intelligent voice teaching aid system in English Teaching
}

\author{
Pinjing Tian ${ }^{1, \text { a }}$ \\ ${ }^{1}$ Jilin Business and Technology College,Changchun,jilin,132000,China \\ asjzpt_wyh@126.com
}

Keywords: intelligent voice teaching system; English teaching; speech synthesis

\begin{abstract}
: with the development of information technology in education, the teaching of various disciplines is trying to apply advanced information technology to teaching, optimize teaching process teaching efficiency. English as a language class, to create the appropriate language learning environment, so that students in the process of exchange. Therefore, the effective use of information technology and information tools to assist English teaching, create an environment, the development of learning resources for English learning, so that students in a rich environment relaxed to learn English language is still the focus.
\end{abstract}

\section{Introduction}

Intelligent voice teaching aid system to standard for students learning environment, let students learn English in a relaxed. English teaching can make use of intelligent voice teaching aid system for students to participate in learning, stimulate students' interest. Through analysis of the present English teaching situation in China, to find a solution to the problem on the basis of this In this study, namely the use of intelligent voice teaching aid system to assist teachers in teaching English. Through the quantitative analysis of the whole class classroom record, understand the application timing, intelligent voice system in the application of classroom teaching link, bring teaching method of English classroom teaching mode, change ${ }^{[1]}$. Through the teaching case fragment of qualitative analysis, grasp the application of intelligent voice teaching system in the English words, sentences, oral communication teaching, situational teaching, and summed up the intelligent voice teaching aid system support for each teaching link, to explore how to apply the teaching function and optimize the process of classroom teaching, improve the teaching effect. In addition, mining intelligent voice teaching aid system has not yet been used in the teaching of using less or function, so as to better assist English teaching.

\section{Analysis of intelligent voice teaching aid system for English teaching support from the whole}

A comparative study of the third math and science teaching project, use the video recording classroom teaching, through the video digital processing, classroom teaching of information encoding, comparative study on the relationship between teaching process and academic achievement. Research on TIMSS video program research project is: the choice of sample class, field recording, statistical analysis and comparative study ${ }^{[2]}$. This study is mainly about the classroom teaching behavior and teaching elements of intelligent voice application time, application links are classified, in objective analysis about teaching methods of intelligent voice teaching aids for the whole class teaching mode, change and bring on the teachers and students in classroom teaching behavior.

Rich and structured to provide classroom teaching of complex information, namely the external knowledge, generate new knowledge can be used in the analysis of teaching process. This process is 
called classroom teaching video information encoding process. The two basic goals of classroom teaching video information coding are as follows: first, to construct the concept of teaching quality, which is directly related, and the two is to effectively reflect the real situation of classroom teaching. Therefore, the information coding includes two aspects of the task, not only to the structure of the teaching, the content of the teacher's teaching design code, but also the teaching process in the event of real-time coding. TIMSS video research project designed a two - way information coding method, the second round of the classroom teachers and students to talk to the coding.

The first round of encoding is performed in the classroom teaching, analysis intelligent voice teaching aid system in all aspects. In this paper, the whole teaching process can be divided into introduction, review and evaluation.

The second round coding is the teachers and students voice of the intelligent speech system. A conversation is a class of sentences or phrases that serve a single purpose in the classroom. Pay attention to the conversation between teachers and students in the classroom teaching, can be more comprehensive analysis of the teaching process, as well as the intelligent voice system for students to create learning opportunities. The second round of encoding session can be divided into 12 categories, which are teacher inspiration, teachers' information, teachers, and students understand the indication of response, instructed students to understand the response, intelligent voice system and intelligent voice system understanding.

\section{Analysis of intelligent voice system on teaching aids support from the micro level}

Two typical cases through the quantitative analysis, the intelligent voice system plays a different role in different aspects of English teaching. In the English words, different situational dialogue teaching can give full play to the various functions of intelligent voice system, combined with pictures, objects, courseware and other teaching resources, adopt various teaching methods to attract the attention of students, stimulate their desire to learn, so that they can gain knowledge and skills through visual impression ${ }^{[3]}$. The following is from the word teaching, sentence pattern teaching, situational teaching, oral communication, and evaluation of teaching, combined with the relevant case fragments, in-depth analysis of the intelligent voice system for English teaching support.

The use of intelligent voice teaching system, promote the teaching of words. Vocabulary is one of the three elements of language. The human thinking activity is carried out with the help of words; the communication of the human mind is realized by the sentences. Combined with the actual situation in the teaching practice, according to the different teaching contents and teaching objects, to adapt the specific circumstances of the flexible teaching methods, fully mobilize the initiative of students learning English, so as to achieve the goal of training.

A word is the smallest unit of language that has a certain form language, which means a certain meaning can be used freely. It is not only the basic unit of language organization, but also the basic structure of reading materials ${ }^{[4]}$. Wilkins, a famous linguist, which once pointed out that no grammar can be well expressed, but no words can express anything. It can be seen that vocabulary is the basis of language learning. Words in English Teaching in primary and secondary schools occupy a large proportion, is the basis for students to master English. In English words teaching, students' correct pronunciation is very important part, because the master degree of speech will directly affect the students' listening and speaking ability, thereby affecting their confidence for learning English.

The use of intelligent voice teaching system, support pattern teaching. Sentence pattern known as sentence structure, is a typical sentence pattern which is based on the structural meaning and 
structural features of a sentence. Through the study of sentence patterns, it can lay a good foundation for students' communication. Which can be integrated grammatical sentences in the pattern of learning, combined with animal toys, pictures, and student learning support patterns?

Through the production of real life scenes in the intelligent voice system, let the real name courseware patterns, reading textbooks in the sentence read aloud, the creation of diversified sentence replace the practice, stimulate learning interest, and increase the opportunity to practice, strengthen students' desire to communicate, so as to achieve the understanding of the sentence the purpose of.

The use of situational teaching supports the intelligent voice teaching system. Students are in physical state of the upheaval, strengthen the outstanding independent spirit of the critical period, they are no longer completely passive adaptation, obey the executants and imitation, but" strive to become active exploration, discovery, selection, the designer". The creation of teaching situation should not only meet the needs of teaching content, but also take into account the psychological characteristics of primary ${ }^{[5]}$. Teachers have the purpose to create a positive emotional color, so that students can directly accept the atmosphere of the situation, to help students better understand the content of teaching, teaching experience in the emotional content. The standard language situation created by the intelligent voice system can mobilize the students to participate in a variety of sensory learning, stimulate learning motivation, learning in a good interaction.

The use of intelligent voice teaching system, oral communication teaching. The purpose of learning words is to make students use the sentences with them in their daily life. Professor He Kelang said that the purpose of children's language learning is to communicate, and in the communication with people in order to quickly master the language. However, oral communication is not a simple combination of words, but the learners to master certain language skills, feelings of meaningful oral communication ${ }^{[6]}$. As the saying goes, the word does not leave, sentence does not leave. Language learning not only stays in the teacher direct students to students or mechanical memory stage, but makes sense in the construction of knowledge.

Speech recognition is a preliminary coding of speech stimuli in the form of auditory. This is the primary level of language comprehension; it is influenced by factors such as context. So, the language should exist in certain circumstances, if left the scene, the language will become a source of water without trees. The teaching of oral English communication should expose students to a certain situation. With the help of an intelligent speech system, it can be used to render and create the scene of language.

The use of the intelligent voice system of the teaching aids. Intelligent voice system not only with the standard language will say "artificial mouth", to create a standard English learning environment for the learners, but also can understand human speech "artificial ear", can carry out automatic evaluation of the pronunciation level using speech recognition technology. Pronunciation evaluation can help teachers and students to revise and improve the level of English pronunciation, and to solve the problem of "difficulty in pronunciation".

Pronunciation is the first step in learning English. The use of intelligent speech system can help teachers to evaluate students' pronunciation in classroom teaching, so as to effectively improve students' English pronunciation. After learning the words and sentences, students read the input will automatically give the pronunciation of the evaluation, manner to the pronunciation of the students to give feedback in a timely. By clicking on "my pronunciation" and "demonstration reading" button, you can compare the pronunciation of the students and the demonstration pronunciation to help students correct the problems in their pronunciation.

The use of intelligent voice teaching system, improve teachers' pronunciation accuracy. The 
evaluation function of intelligent speech system not only helps the students to learn English, but also promotes the improvement of their own level. At present, due to the quality of the teachers in the less developed areas, especially in rural areas, there are many problems in English pronunciation. The use of pronunciation evaluation function can help teachers in preparing lessons or other extra-curricular learning to correct the non-standard pronunciation of English, teachers' English level and improve the quality of a certain role in promoting.

Teachers prepare lessons can be used to evaluate the function of pronunciation evaluation. The content will be taught to the students, compared with the standard pronunciation, test their pronunciation is accurate ${ }^{[7]}$. If there is not the standard pronunciation of the situation, through the standard pronunciation of the self training tape, to ensure accurate delivery of teaching contents. English teachers in the preparation process to solve the problem of pronunciation is not allowed, can make students become the real beneficiaries. Correct pronunciation problems. Language teaching is special, in addition to the teaching content of each lesson; the entire teaching activities are required to complete the English organization. Because the teacher's level is uneven, widespread pronunciation or "English dialect" phenomenon, improve English teachers' literacy, through teaching and research activities in a variety of ways, intelligent voice system evaluation function can fully support ${ }^{[8]}$. Through organized and spontaneous learning activities, teachers can conduct self evaluation at any time, according to the assessment feedback, each teacher to solve their pronunciation problems, gradually improve their English level and overall quality.

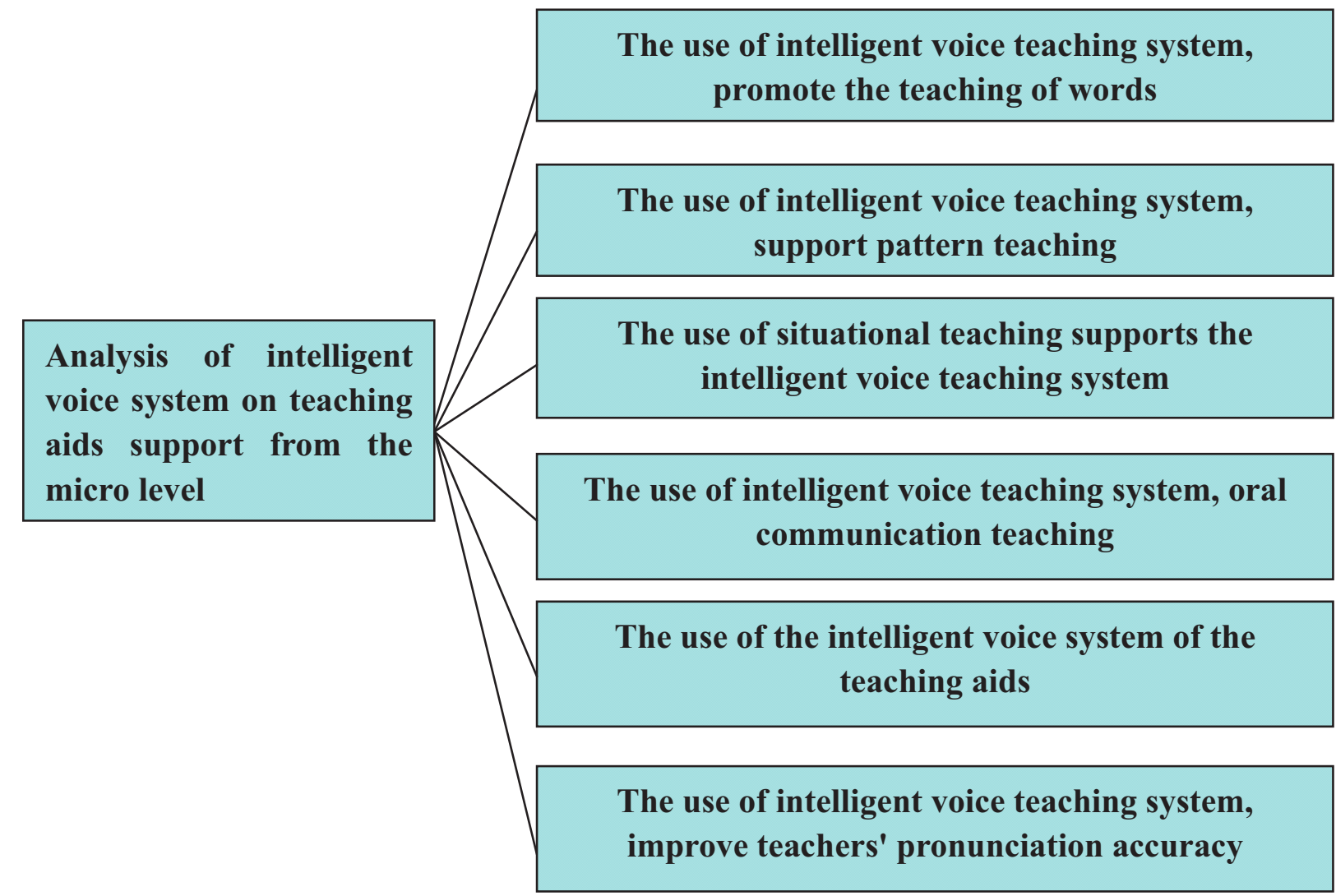

Fig1. Analysis of intelligent voice system on teaching aids support from the micro level

\section{Conclusion}

The development of intelligent voice system based on speech synthesis, speech evaluation technology, the English Teaching in the "human-computer interaction" learning, brings convenience 
to the English teaching, but also give full play to the information technology in the English classroom teaching effect. The use of voice evaluation technology can help teachers and students to evaluate pronunciation, timely correct pronunciation problems. Based on the analysis of the classroom memoir, this paper summarizes the application of the intelligent voice system in the different aspects, and makes an in-depth analysis. In addition, it also discovers in the pronunciation evaluation function, discussed in the classroom teaching should be how to make good use of this feature to evaluate students' pronunciation, to provide the reference for teachers.

Teachers should be in accordance with the new English curriculum standards of primary in English teaching, according to the psychological characteristics of students need the rational intelligent voice system, and make the objects, courseware resources to effectively integrate, make students actively involved in learning, help students intuitively grasp English words, sentences and dialogue, to construct the meaning of the English language in the real situation.

\section{References}

[1]David Jonassen .Constructivism and Computer-Mediated Communication in Distance Education [J].The American Journal of Distance Education, 2013(2):23-25

[2]Brent G. Wilson.Metaphors for Instruction: Why We Talk about Learning Environments [J].Educational Technology, 2015 (9):70-73

[3] Dai Weidong, Liu Chunyan. The new development of learning theory and the evolution of foreign language teaching model [J]. Foreign language circle, 2014 (4):56-58

[4] $\mathrm{Wu}$ Chang. Discuss the development of the theory of distance foreign language learning in China [J]. Modern distance education research, 2015 (3):34-38

[5] The integration of information technology and curriculum integration theory analysis thinking and construction of new [J]. China audio-visual education, 2015 (7):79-81

[6] Liu et al. Research on the theory of language learning and teaching Chinese as a foreign language [J]. Language application, 2016(2):66-68

[7] Yang Lan, Liu Feng Hui. Language theory, language learning theory and foreign language teaching [J]. Journal of Tibet University for Nationalities, 2013 (7):56-58

[8] Guo Jingping. From the theory of behavior to the theory of nature: the inheritance and development of language learning theory [J]. Journal of Xuzhou Normal University, 2015 (7):12-15 